\title{
POBOLJŠANJE MEDIJSKE KOMPETENTNOSTI GRAĐANA U FUNKCIJI OPTIMALNOG KORIŠTENJA POTENCIJALA ONLINE I OFFLINE MEDIJA
}

„Tehnologija je vrlo zabavna, ali se u njoj možemo i ugušiti. Informacijska magla može otjerati znanje."

Daniel Boorstin

\section{- Sažetak -}

Da bi potencijale informacijsko-komunikacijske tehnologije optimalno iskoristili za svoj prosperitet, građani, osim pristupa toj tehnologiji, trebaju imati i određeno komunikološko znanje, odnosno razvijati medijsku kompetenciju. Medijsko obrazovanje ne može korjenito promijeniti savremeno medijsko tržište koje korisnike tretira kao konzumente, a ne kao građane, ali može doprinijeti njegovim promjenama razvijajući kognitivne, tehničke, kulturološke $i$ estetske kompetencije korisnika za razumijevanje i korištenje savremenih medija, kao i ekonomskih i ideoloških zakonitosti po kojima funkcionišu. Koncept medijskog obrazovanja u BiH nije dovoljno razvijen niti u javnosti niti u akademskoj zajednici, a dostupni podaci ukazuju da će njegovo integrisanje u obrazovne programe biti dugotrajan i težak proces.

Ključne riječi: komunikacijska tehnologija, korisnici, medijska kompetencija, medijski sadržaji, kritička svijest.

1 Doc. dr. Zarfa Hrnjić Kuduzović, Fakultet političkih nauka, Univerzitet u Sarajevu 


\section{Uvod}

Intenzivan razvoj informacijsko-komunikacijske tehnologije postavlja brojne izazove, kako pred novinare i medijsku industriju uopšte tako i pred korisnike. Tehnička opremljenost korisnika uređajima poput (klasične, digitalne ili interaktivne) televizije, zatim kompjuterima, iPadima, iPhoneima i sličnim uređajima nije dovoljna da bi oni optimalno koristili njihove kapacitete. Za to im je potreban određeni nivo tehničkog i komunikološkog znanja, odnosno medijska kompetentnost. Razvoj masovnih medija i uopšte sredstava za komunikaciju je i u ranijim epohama bio usko povezan sa razvojem pismenosti i obrazovanja među građanima.

U kojoj će mjeri građani koristiti komunikacijske tehnologije za svoj boljitak kreirajući i distribuirajući medijske sadržaje, pokrećući određene teme u medijima, komentarišući i kritikujući društvene fenomene zahvaljujući dobroj informisanosti i znanju, a koliko će biti žrtve medijske manipulacije zavisi u velikoj mjeri od njihovog poznavanja novih tehnologija te sposobnosti razlikovanja vjerodostojnih od manipulativnih informacija. Upravo zbog toga se u nekim, prvenstveno onim razvijenijim zemljama, provodi medijsko obrazovanje učenika i studenata, a njegovo uvrštavanje u nastavne programe zagovaraju brojne međunarodne institucije i organizacije. Na međunarodnom nivou, pitanje medijske kompetencije inicirao je UNESCO 70-ih godina XX vijeka da bi 1982. godine 19 evropskih zemalja u Grunwaldu (Njemačka) potpisalo Konvenciju o medijskom obrazovanju². UNESCO-ove Preporuke o edukaciji za medije i digitalno doba ${ }^{3}$ usvojene u Beču 1999. godine prihvatile su 33 države.

Medijska kompetencija podrazumijeva posjedovanje znanjai vještina potrebnih za optimalno korištenje potencijala komunikacijske tehnologije, te razumijevanje načina na koji mediji funkcionišu i sposobnost kritičkog analiziranja medijskih

2 Polazeći od jaza između obrazovne prakse u kojoj je korištenje, ali i analiziranje u masovnim medijima neopravdano zanemareno i stvarnosti u kojoj mladi u nekim državama provode više vremena uz medije nego u školi, preporučene su mjere za razvoj kritičkih sposobnosti publike. One podrazumijevaju uvođenje programa medijskog obrazovanja od predškolskih do univerzitetskih ustanova, kao i cjeloživotnu edukaciju odraslih; provođenje obuke za nastavnike radi povećanja medijskih znanja i vještina i uvođenje adekvatnih nastavnih metoda; podsticanje istraživanja čiji će rezultati doprinijeti medijskom obrazovanju, te podršku država UNESCO-ovim inicijativama i projektima za jačanje međunarodne saradnje u medijskom obrazovanju.

http://www.unesco.org/education/pdf/MEDIA_E.PDF, pristupljeno 10. 9. 2012.

3 Njima se naglašava važnost uključivanja medijske edukacije kako u programe formalnog obrazovanja tako i one neformalne. Potencira se obuka o novim komunikacijskim tehnologijama i njihovom potencijalu za poboljšanje kvaliteta života građana $i$ to u razvijenim i nerazvijenim državama, u normalnim kao i u vanrednim situacijama.

http://www.mediamanual.at/en/pdf/recommendations.pdf, pristupljeno 10. 9. 2012. 
sadržaja. Dakle, cilj medijskog obrazovanja je podstaći i osposobiti korisnike za medijski aktivizam i kritički odnos prema medijskoj i društvenoj stvarnosti, te na taj način spriječiti manipulaciju građanima i doprinijeti demokratizaciji medija i društva.

Lin Masterman ${ }^{4}$ je naveo ključne razloge koji medijsko obrazovanje čine nužnim:

- visoka potrošnja medija i prezasićenost do koje stižemo

- ideološki značaj medija, posebno imajući u vidu reklame

- pojava informacionog rukovođenja u preduzećima

- narastajući značaj vizuelne i informacione komunikacije u svim domenima

- očekivanja mladih da budu obrazovani tako da mogu razumjeti svoje doba

- nacionalni i međunarodni porast privatizacije svih informacionih tehnologija

\section{Medijsko obrazovanje u BiH}

Navedeni razlozi, a ni potenciranje međunarodne zajednice za razvoj medijske pismenosti za sada očito nisu dovoljni za ozbiljan pristup medijskom obrazovanju u Bosni i Hercegovini. Analiza nastavnih planova i programa koju je 2011. godine provela Regulatorna agencija za komunikacije pokazala je da edukacija nastavnika, učenika, roditelja i medijskih korisnika uopšte o novim tehnološkim mogućnostima medija, o produkcijskim i ekonomskim načelima njihovog funkcionisanja te opasnostima od njihove zloupotrebe $i$ mehanizmima zaštite nije na odgovarajućem nivou. Bosna i Hercegovina u ovom segmentu ne ispunjava standarde Evropske unije, a medijsko obrazovanje još uvijek nije prepoznato kao bitna komponenta niti medijske politike niti obrazovnih programa. Medijsko obrazovanje je slabo razvijen koncept ne samo u javnosti nego i u akademskoj zajednici. Obrazovne institucije u $\mathrm{BiH}$ još nisu pokazale odgovarajući interes za njim, a ni u naučnim krugovima koncept nije dovoljno razvijen. Posljedično nema ni naučnih istraživanja iz ove oblasti, a ni mehanizama za praćenje medijske pismenosti ${ }^{5}$. Prvi projekat medijske pismenosti u BiH pokrenut je tek 2003. godine. Mediacentar Sarajevo inicirao je javnu debatu o potrebi uvođenja medijskog obrazovanja u srednje škole u $\mathrm{BiH}$, te organizovao radionicu o medijskoj pismenosti za nastavnike.

4 Prema Gone, Žak (1997). Medijsko obrazovanje. Beograd: Clio, str. 25.

5 www.media.ba/mcsonline/bs/vijest/rak-medijska-pismenost-u-bih-ne-ispunjava-zahtjeve-eu, pristupljeno 9. 4. 2011. 
Projekat je nastavljen objavljivanjem zbornika Medijska pismenost $i$ civilno društvo 2005. godine, a 2007. godine objavljen je zbornik Stereotipizacija: predstavljanje žena u štampanim medijima u jugoistočnoj Evropi. Internews u Bosni i Hercegovini je 2012. godine pokrenuo inicijativu podizanja nivoa medijske pismenosti, te $u$ tom cilju provodi aktivnosti povezivanja različitih društvenih aktera zainteresovanih za ovu oblast ${ }^{6}$. Njihova saradnja trebala bi rezultirati konkretnim akcijama za poboljšanje kvaliteta formalnog obrazovanja iz oblasti medijske pismenosti u institucijama gdje ono postoji, odnosno osposobljavanjem građana putem neformalnih oblika edukacije za prepoznavanje manipulativnih i neprofesionalnih medijskih sadržaja. U okviru projekta Podrška kvalitetu i razvoju novih medijskih platformi $i$ izvora, ova organizacija nudi finansijsku i tehničku podršku novinarima, kao i građanima, za efektnije korištenje digitalnih medija. Nekoliko udruženja građana koja su dobila grantove osnovalo je web portale koji funkcionišu kao crowdsourcing platforme koje omogućavaju građanima da prijave probleme iz određenih oblasti, te ih podstiču na građanski aktivizam.

Rezultati pomenute analize RAK-a pokazuju da će borba za medijsko obrazovanje u $\mathrm{BiH}$ biti duga i teška. Napredak u ovoj oblasti zahtijeva sistematičan pristup medijskom obrazovanju $\mathrm{u}$ nastavnim programima, mnogo veći broj istraživanja za njegovo akademsko utemeljenje u $\mathrm{BiH}$, te odgovarajuće seminare i radionice za obuku nastavnika.

Zagovornici teze o aktivnoj publici shvaćaju je kao zrelu, obrazovanu i voljnu da se kognitivno angažuje u dekodiranju medijskih sadržaja. Međutim, između ovako viđene ,idealizovane” publike i one stvarne postoji značajna diskrepancija. Jaz u znanju među publikom se produbljuje, njena fokusiranost na sadržaj uslijed informacijske prezasićenosti opada, kao i interes za vijesti. Ovi trendovi najizraženiji su među mlađom publikom (16-34 godine) i nisu ograničeni na neke države nego su istinski globalni.

\section{Varijable utjecaja na ponašanje online korisnika}

Nivo obrazovanja prilično je dobar pokazatelj medijskih navika i informacijskih potreba publike. Visokoobrazovani zaposlenici s višim prihodima informisanost smatraju važnom za svoj posao i oni mnogo češće izjavljuju da im je važno biti u toku s vijestima u odnosu na manje obrazovane zaposlene osobe s nižim prihodima ${ }^{7}$. Online korisnici s višim nivoom formalnog

6 www.internews.ba, pristupljeno 30. 10. 2012.

7 Vidjeti u Pew Research Center Biennial News Consumption Survey (2008). Audience Segments in a Changing News Environment: Key News audiences now blend online and traditional sources. Pew Research Center for The People and The Press. 
obrazovanja češće tragaju za finansijskim, političkim i informacijama iz Vlade (Howard, Rainie i Jones, 2001), vijestima, informacijama o proizvodima, te su skloniji aranžiranju putovanja online i korištenju interneta u poslovne svrhe (Madden, 2003). Korisnici koji imaju pristup internetu s više mjesta više ga koriste za traženje informacija o zdravlju, istraživačkim projektima, proizvodima koje kupuju, kao i za obavljanje bankovnih transakcija (Hassani, 2006) $)^{8}$. Eszter Hargittai i Amanda Hinnant (2009) su na osnovu rezultata svog empirijskog istraživanja zaključili da obrazovanost ispitanika utječe na sklonost ljudi za posjećivanjem web stranica s informacijama o poboljšanju kvaliteta života. Ispitanici koji su prijavili da imaju veće vještine češće su posjećivali web portale koji mogu doprinijeti poboljšanju životnih prilika i na osnovu čijih informacija posjetioci mogu uvećati svoj duhovni i finansijski kapital (617). Upravo u tom smjeru vodi i medijsko obrazovanje: poboljšanju znanja i vještina korisnika kako bi optimalno koristili potencijale klasičnih i novih medija u svrhu poboljšanja kvaliteta života.

$\mathrm{U}$ analizama interaktivnih i demokratskih potencijala medija, posebno interneta, ističe se jednostavnost i lakoća s kojom korisnici mogu proizvoditi i objavljivati sadržaje. Kvantitet dostupnih sadržaja u offline i online medijima ponekad se pogrešno poistovjećuje s kvalitetom ili se u najmanju ruku vjeruje kako će se iz ogromne količine informacija iskristalisati one kvalitetne koje će onda korisnici prepoznati kao takve. Međutim, činjenica da korisnici vrlo lako mogu objavljivati sadržaje ne samo da ne znači mnogo za razvoj demokratije nego čak može biti i opasna za nju bez odgovarajuće medijske kompetencije. Nove generacije korisnika sklone su objavljivanju svojih stavova, pogotovo u virtualnom okruženju, iako većini njih nedostaje odgovarajući nivo informisanosti i znanja, kao i kritički odnos prema društvenoj zbilji. Mladi vrlo lako usvajaju naviku snimanja i objavljivanja dijelića stvarnosti koji im se čine zanimljivim, a koje onda putem interneta dijele sa svijetom. Ali, tim otrgnutim djelićima stvarnosti nedostaje kontekst, a njihovim autorima razumijevanje funkcionisanja društvenih sistema i njihovih institucija. Tu prazninu korisnici kompenzuju kreiranjem sopstvenih sadržaja i vlastitim interpretacijama. Mogućnost da svako ko ima pristup novim komunikacijskim tehnologijama može objavljivati demokratsko je pravo, ali ŠTA se objavljuje? Na kojim i kakvim izvorima i činjenicama je ono utemeljeno? Koliko je njihov autor kompetentan? Ovo može biti vrlo plodno tlo za površnost, senzacionalizam i manipulaciju.

8 Prema Hargittai, E., Hinnant, A. (2009). Digital Inequality: Differences in Young Adults' Use of the Internet. Communication Research. 35 (5), str. 607. 
Longitudinalno istraživanje provedeno u Velikoj Britaniji ${ }^{9}$ ruši mit o zavidnoj informacijskoj pismenosti generacija rođenih ili odgojenih u doba interneta. Iako ovi korisnici s lakoćom koriste kompjutere, koje osjećaju vrlo bliskim, oni su vrlo ovisni o web pretraživačima, uglavnom „konzumiraju” video-sadržaje, malo čitaju, tekstovima takođe pristupaju kao vizuelnim sadržajima, odnosno više ih pregledaju nego što ih čitaju. Količina vremena koju mladi korisnici provedu na pojedinačnim web siteovima i sadržajima kada pretražuju pokazuje da im nedostaje kritički odnos prema onome što „konzumiraju”, odnosno da nedovoljno vremena provode u evaluiranju vjerodostojnosti i relevantnosti informacija.

Ovakav odnos prema informacijama nije iznenađujući u vremenu neprijateljski naklonjenom štampanim medijima i čitanju uopšte. $\mathrm{Na}$ svjetskom forumu novinskih urednika 2008. godine pad čitanosti printanih medija među mladim osobama identifikovan je kao jedna od najvećih prijetnji budućnosti novina ${ }^{10}$. Interesovanje mladih korisnika kontinuirano pada i za vijesti objavljene u ostalim medijima. Rijetki među njima koji „konzumiraju” vijesti vole kada su one objavljene na satiričan način i kad se završe nečim zabavnim. Mladi gledaoci odbijaju tradicionalne informativne formate i njihovu konvencionalnu ozbiljnost. Kao prezentere vijesti preferiraju osobe koje to čine na satiričan i ironičan način u odnosu na ozbiljne voditelje $u$ odijelima $^{11}$.

Empirijskim istraživanjima utvrđeno je da su čitaoci novina politički zainteresovaniji i angažovaniji (Bogart, 1989; McLeod i Perse, 1994). Ljudi koji često čitaju novine više raspravljaju o političkim temama u svakodnevnoj konverzaciji nego neredovni čitaoci. Među redovnim čitaocima većije procenat onih koji glasaju na izborima za predstavnike vlasti, dok se neredovni čitaoci

9 University College of London (UCL) (2008), ,Information Behaviour of the Researcher of the Future", Centre for Information Behaviour and the Evaluation of Research (CIBER), www.bl.uk/news/pdf/googlegen.pdf.

10 Philip Mayer smatra da je dobra vijest u vezi s online čitaocima što su oni uglavnom novi čitaoci, tj. oni koji inače ne čitaju printana izdanja novina i što su uglavnom mlađi, odnosno predstavljaju onaj segment publike koji štampane novine ne mogu da dosegnu i koje su uzrok dugoročnog gubitka za novine (2004:221). Do sada raspoloživi empirijski podaci, međutim, ne potkrepljuju u potpunosti hipotezu o tome da će vrlo mladi online čitaoci postepeno supsituisati starije čitaoce printanih izdanja novina koji ne preferiraju čitanje online vijesti. Suprotno tome, ne postoji oštra podjela na offline i online korisnike. Još uvijek je mali broj osoba koje se oslanjaju isključivo na online vijesti (osim u pojedinim zemljama poput Južne Koreje u kojima veći broj ljudi vijesti konzumira online nego offline). Raspoloživi podaci ukazuju na tendenciju dobro informisanih čitalaca da vijesti koje su pročitali dopune online ponudom. News in the Internet Age New Trends in News Publishing 2010: 76.

11 Associated Press (2008): A New Model for News: Studying the Deep Structure of Young-Adult News Consumption, str. 44. 
novina uglavnom oslanjaju na televiziju kao izvor vijesti i manje su politički aktivni. Leo Bogart zaključio je i to da su oni neredovni čitaoci mlađi od 18 godina vrlo nestalni i gotovo potpuno neupućeni u vijesti, uključujući i one iz njihove lokalne zajednice ${ }^{12}$.

\section{Aktivni i kritički neosviješteni korisnici}

Upravo iz ovakvih razloga, a u nastojanju da poboljšaju informisanost mladih, neke zemlje realizuju edukativne projekte čiji je cilj povećati čitanost novina. Srednjoškolcima i studentima se u dužem vremenskom periodu (npr. godinu dana) besplatno dostavljaju novine koje se inače plaćaju kako bi se kod njih razvila i/ili sačuvala navika čitanja i zainteresovanost za ozbiljna društvena zbivanja. Među državama koje provode ovakve projekte medijskog opismenjavanja koji podrazumijevaju besplatnu distribuciju novina, kurseve povećanja informisanosti među srednjoškolcima, te upotrebu novina $u$ nastavnom procesu prednjače Njemačka, Francuska, SAD i Japan ${ }^{13}$.

Potreba za medijskim obrazovanjem u malim državama kakva je i Bosna i Hercegovina još je naglašenija zbog slabo zastupljene domaće produkcije i njihove podložnosti medijskom imperijalizmu ${ }^{14}$. Iako zagovornici teze o aktivnoj publici naglašavaju ulogu novih komunikacijskih tehnologija $u$ većem angažovanju pojedinaca pri tumačenju medijskih sadržaja, empirijske studije pokazuju da mlađim generacijama uveliko nedostaje kritičko promišljanje percipiranih sadržaja ${ }^{15}$. Studije takođe ukazuju na neodrživost antiteze o aktivnoj publici s jedne i kulturnom imperijalizmu s druge strane. U dosadašnjim teorijskim razmatranjima teza o aktivnoj publici posmatrana je, kako zapaža Yu Shi (2010), kao izazov američkoj kulturnoj invaziji. Polazilo se od pretpostavke da je publika, ako je aktivna u kreiranju i/ili selekciji medijskih sadržaja, imuna na manipulaciju i utjecaj ideoloških potkodova infiltriranih u njih. Stoga je poimanje publike kao korisnika predstavljano kao antipod publici kao konzumentima. Međutim, rezultati novijih studija pokazuju da publika aktivno traži i koristi sadržaje, ali da joj nedostaje

12 Modifikovano prema Perse, E. (2001). Media Effects and Society. Mahwah, New Yersey i London: Lawrence Erlbaum Associates, Publishers, str. 95.

13 Vidjeti detaljnije u OECD (2010), News in the Internet Age: New Trends in News Publishing, OECD Publishing, str. 118.

14 Utemeljenju i razvoju teorije kulturnog i medijskog imperijalizma najviše su doprinijeli Armand Matterland (1979), Herbert Schiller (1991) i Oliver Boyd Barrett (1977).

15 Shi, Yu (2010): Product Placement and Digital Piracy: How Young Chinese Viewers React to the Unconventional Method of Corporate Cultural Globalization. Communication, Culture \& Critique 3: $435-463$. 
kritičkog odnosa prema medijskoj stvarnosti, te da je podložna utjecaju ideologije kodirane u medijskim sadržajima (Kraidy 2005, Herman and McChesney (1997), Oliveira (1993), Schiller (1991), Morley (2006: 104), te prikrivenog oglašavanja i advertaismenta u sadržajima koji pristupaju publici kao potrošačima, a ne kao na građanima (DeLorme i Reid, 1999; Olson, 2004, Pompper \& Choo, 2008). Drugim riječima, u teorijskim razmatranjima često postavljena dihotomija korisnik - konzument, nema empirijsko uporište i predstavlja pretjeranu simplifikaciju odnosa između publike, medija i ideologije u njihovim sadržajima. Istraživanje Yu Shija pokazalo je da su svi njegovi ispitanici (150 mladih Kineza sa kojima je obavio dubinski intevju) bili aktivni gledaoci u smislu da su tragali za sadržajima koji ih interesuju i da su na taj način činili napor da ostanu ukorak s razvijenim državama. Za njih je gledanje američkih programa, kao i posjedovanje brandova koji su prikriveno oglašavni u tim medijskim sadržajima statusni simbol. Pokazalo se da jačanje pozicije publike u smislu veće kontrole nad medijskim sadržajem i većih mogućnosti izbora nije u suprotnosti s kulturnim imperijalizmom, konzumerizmom, homogenizacijom, tj. moći korporacija. Isto istraživanje pokazalo je da mladi u Kini o brendovima ne razmišljaju kritički. To ne znači da oni nisu znali za probleme u vezi sa proizvođačima brendova koje oni vole (npr. elektronskom otpadu, zagađenju prirode, lošim uslovima u kojima rade radnici i sl.). Međutim, oni su apolitični, bez izgrađene kritičke svijesti. Trenutni neoliberalni ambijent ide na ruku konzumerizmu, tako da se i mediji ne obraćaju građanima nego potrošačima (isto, 455). Todd Gitlin upozorava da nas komercijalni mediji postepeno uvjeravaju da mislimo o sebi kao o potrošačima, a ne građanima, te da se tako i ponašamo. Tako se i za javne probleme (npr. zagađenja zraka) traže privatna rješenja (npr. kapi za oči), a takva komercijalizacija ponašanja građana vodi ka komercijalizaciji javne sfere. Takvi mediji od homo sapiensa stvaraju homo vidensa u čijoj spoznaji slika dominira nad tekstom čineći ga nesposobnim za apstraktno mišljenje i kritičko promišljanje (Sartori, 1999), a brand, odnosno materijalno, mjerilo ljudske vrijednosti. Na tom fonu, viđenje publike prvenstveno kao posmatrača, a ne učesnika u komunikacijskom procesu (Elliot, 1972) ne čini se nikako anahronim. Segmentacija publike disperzovane oko desetina i stotina kanala koji promovišu konzumeristički stil života samo povećava socijalnu nejednakost desenzibilizujući gledaoce za potrebe i interese drugih (Turow, 1997). Udaljavanje socijalnih slojeva, izopštenost siromašnih koji ne mogu participirati u dominantnoj konzumerističkoj i medijskoj kulturi (onih koji nemaju pristup internetu, koji ne govore engleski, koji ne mogu 
priuštiti skupe brandove niti sugerisani stil života), frustracija mlađih na konzumerističkim vrijednostima odgojenih generacija, od kojih ogromna većina neće moći ostvariti nametnute prohtjeve - samo su neke od socijalnih konsekvenci takve medijske kulture.

\section{Zaključna razmatranja}

Publika nije bespomoćna. Ona se može oduprijeti dominantnim značenjima medijskih poruka ${ }^{16}$, ona ima određenu moć za medijski aktivizam i može u objektivnom i virtualnom okruženju pokretati kampanje za bojkot ili čak zabranu određenih medija i medijskih sadržaja, kao i kompanija i njihovih brandova. Ali, napredna komunikacijska tehnologija sa svim svojim interaktivnim potencijalima sama po sebi nije dovoljna za socijalno angažovanu i kritički osviještenu publiku. Pod maskom slobode izbora publike kao demokratske alternative paternalističkom odnosu medija, interaktivni potencijal komunikacijske tehnologije koristi se za jačanje tržišnog modela u kojem preferencija publike odlučuje o sudbini medijskih sadržaja. To je model u kojem se medijski sadržaji proizvode prema željama, ali ne i potrebama publike, što je trijumf koji ne zaslužuje aplauz (Tracey, 1998). Osim tehnološkog razvoja, neophodna je kompetentnost publike za kreativno i kritičko medijsko izražavanje. Medijsko obrazovanje ne može samo korjenito promijeniti savremeno medijsko tržište, ali može doprinijeti njegovim promjenama razvijajući kognitivne, tehničke, kulturološke i estetske kompetencije publike za razumijevanje i korištenje savremenih medija, kao i ekonomskih i ideoloških zakonitosti po kojima funkcionišu. Jedan od vodećih teoretičara medijske kulture današnjice Douglas Kellner u razvijanju medijske kompetencije i aktivizma vidi šansu za pobjedu nad „kulturološkim varvarizmom” i načinom rada „monstruoznih konglomerata” (2004: 548-549). U tom cilju, nije dovoljno strategijom informatizacije društva omogućiti pristup savremenim medijima, nego ona treba obuhvatati i obrazovno-odgojnu komponentu u pristupu masovnim medijima. U suprotnom, efekti mogu biti

16 Stuart Hall (1973) kao najznačajniji predstavnik birminghamske škole ukazao je na mogućnosti različitog dekodiranja medijskih sadržaja od strane publike. Iako se kodiranje sadržaja odvija prema određenim standardima i principima koje ustanovljavaju medijske organizacije zastupajući određene vrijednosti, dekodiranje sadržaja zavisi od situacije u kojoj se publika nalazi. Mediji enkodiraju sadržaje tako da potvrđuju dominantne strukture moći. Međutim, recipijenti mogu dekodirati sadržaje sasvim drugačije nego što mediji očekuju, pa čak i suprotno njihovim intencijama i ugrađenim semantičkim kodovima. Na polisemičnost medijskih tekstova ukazao je i John Fiske. Barrie Gunter i Jill McAleer (1997) zaključili su da „gledaoci nisu prazne posude - pa čak ni oni mladi. Oni ne prihvaćaju pasivno sve što televizija kaže ili im pokaže (39)." 
kontraproduktivni jer bi opsjednutost tehnikom na koju upozorava Francis Ball mogla rezultirati nadvladavanjem mogućeg nad korisnim.

Zbog čega ne koristiti elektronsku agendu ako nije skuplja od papirne? Zašto ne ponijeti svoj portabl telefon u restoran kada ne zahtijeva više prostora od kutije cigareta? .... Zašto u udarnim vijestima ne prenijeti direktno kako irački skudovi bombarduju Tel Aviv, budući da su raspoloživi satelitski snopovi unaprijed plaćeni?... Zakon tržišta sve više daje preimućstvo trenutnom i uzbudljivom: na tom neizvjesnom terenu, u štampi ili na ekranu, tekst će teškom mukom uspjeti da na početku XXI vijeka izdrži poređenje (1997: 46).

\section{IMPROVEMENT OF MEDIA COMPETENCES OF CITIZENS FOR OPTIMAL USAGE OF ONLINE AND OFFLINE MEDIA POTENTIALS}

\section{- Abstract -}

In order to utilize optimally potential of information and communications technologies, besides access to the technology, citizens should have certain communicology knowledge and develop media competence. Media education cannot radically change the contemporary media market that treats its users as consumers, not as citizens, but can contribute to changes by developing cognitive, technical, cultural and esthetic competence to understand and use of modern media, as well as economic and ideological principles by which it operates. The concept of media education in Bosnia and Herzegovina is not sufficiently developed neither in the public sphere nor in the academic community, and the available data indicate that its integration into the educational programs will be lengthy and difficult process.

Key words: communication technology, users, media competence, media content, critical awareness. 


\section{Literatura}

- Ball, F. (1997). Moć medija, Clio, Beograd.

- Elliot, P. (1974), Uses and gratificiations research: a critique and a sociological alternative. U Blumler, J. i Katz, E. (ur.), The Uses of Mass Communications: Current Perspectives of Gratificiations Research, Sage Publications, Beverly Hills.

- DeLorme, D. E., Reid, L. N. (1999), Moviegoers' Experience and Interpretations of Brands in Films Revisited. Journal of Advertising, 28 (2): 71-95.

- Douglas, K. (2004), Medijska kultura,Clio, Beograd.

- Gitlin, T. (2000), Prime time ideology. U Newcomb, H. (ur), Television, the critical view (str. 574-594), Oxford University Press, Oxford.

- Gone, Ž. (1997)., Medijsko obrazovanje, Clio, Beograd.

- Gunter, B., Jill, M. (1997), Children and Television, Routledge, London and New York.

- Hall, S. (1973), Encoding and Decoding in the Television Discourse, CCS, Birmingham.

- Hargittai, E., Hinnant, A. (2009), Digital Inequality: Differences in Young Adults' Use of the Internet. Communication Research. 35 (5): 602-621.

- Herman, E., McChesney, R. (1997), The Global Media: the new missionaries of corporate capitalism, Cassell, London.

- Kraidy, M. (2005). Hybridity or, The Cultural Logic of Globalization, PA: Temple University Press, Philadelphia.

- Mayer, P. (2004). The vanishing newspaper: Saving journalism in the information age. Columbia, Missouri: University of Missouri Press.

- McLeod, D., Perse, E. (1994). Direct and indirect effects of socioeconomic status on public affairs knowlede. Journalism Quarterly, 71 (2): 433-442.

- Morley, D. (2006), Globalisation and Cultural Imperialism Reconsidered: Old Questions in New Guises U Curran, J.; Morley, D, (ur.) Media and Cultural Theory, Routledge: Oxon.

- Oliveira, S. (1993), Brazilian Soaps Outshine Hollywood: Is Cultural Imperialism Fading Out? U Nordenstreng, K.; Schiller. H.: Beyond national sovereignty: international communication in the 1990s. Norwood, NJ: Ablex Pub. Co.

- Perse, E. (2001), Media Effects and Society, Lawrence Erlbaum Associates, Publishers, Mahwah, New Yersey i London.

- Pew Research Center Biennial News Consumption Survey (2008), Audience Segments in a Changing News Environment: Key News audiences now blend online and traditional sources. Pew Research Center for The People and The Press. 
- Pompper,D., Choo, Y. F. (2008), Advertising in the Age of TiVo:

Targeting Teens and Young Adults With Film and Television Product Placements. Atlantic Journal of Communication, 16 (1): 49-69.

- Sartori, G. (1999), Homovidens, Editori Laterza, Roma - Bari.

- Schiller, H. (1991), Culture, Inc.: The Corporate Takeover of Public Expression, University Press, Oxford.

- Tracey, M. (1998), The Decline and Fall of Public Service Broadcasting, University Press, New York: Oxford.

- Turow, J. (1997), Breaking Up America: Advertisers and the New Media World. Chicago i London: University of Chicago Press.

- Associated Press (2008), A New Model for News: Studying the Deep Structure of Young-Adult News Consumption. www.ap.org/newmodel.pdf.

- OECD (2010), News in the Internet Age: New Trends. U News Publishing, OECD Publishing University College of London (UCL) Information Behaviour of the Researcher of the Future, Centre for Information Behaviour and the Evaluation of Research (CIBER), www.bl.uk/news/pdf/googlegen.pdf.

- www.internews.ba www.media.ba/mcsonline/bs/vijest/rak-medijska-pismenost-u-bih-neispunjava- zahtjeve-eu. 